\title{
Material para procedimentos endovasculares da aorta
}

\author{
Rodrigo de Castro BERNARDES
}

A cirurgia endovascular é um dos maiores avanços no tratamento dos aneurismas e dissecções da aorta, oferecendo ao paciente a possibilidade de uma terapêutica eficaz com agressividade mínima e recuperação rápida. Quando apresentamos ao paciente esta alternativa cirúrgica devemos estar cientes que uma complicação de uma cirurgia por via endovascular transforma um procedimento eletivo em uma cirurgia de URGÊNCIA, com altas taxas de morbimortalidade. Sabemos que o procedimento convencional tem mortalidade baixa e ótimo resultado a longo prazo. Portanto, a cirurgia endovascular deve ser indicada sempre após avaliação minuciosa da anatomia do aneurisma sob os seus mais diversos aspectos. O cirurgião deve estar sempre preparado para o procedimento conhecendo as técnicas e tendo à sua disposição um arsenal completo de material que tentaremos listar a seguir.

Ambiente: A cirurgia endovascular dos aneurismas é um procedimento cirúrgico e deve ser sempre realizado em ambiente apropriado, devendo o cirurgião contar com todo o apoio necessário como se o procedimento fosse ser realizado por via aberta.

-Reserva de hemoderivados.

-Material para anestesia.

-Sala cirúrgica aparelhada com monitorização completa.

-Caixa de material cirúrgico para cirurgia vascular.

-Focos de iluminação.

-Bisturi elétrico.

-Mesa rádio-transparente.

-Intensificador de imagem de alta qualidade.

Equipe: A equipe cirúrgica deve ser composta de um cirurgião com experiência em cirurgia vascular e endovascular, dois auxiliares e instrumentadora. A equipe de anestesia deve estar presente e preparada para a realização de anestesias regional e/ou geral.

Via de acesso: A dissecção de uma ou duas artérias femorais deve expor a femoral comum e suas bifurcações. As artérias femorais comuns serão puncionadas e preparadas com introdutor 7 FF. Em alguns casos, pode ser necessária abordagem retro-peritoneal dissecando-se a artéria ilíaca comum, onde anastomosamos uma prótese reta de Dacron de 8mm que servirá de acesso para a introdução da endoprótese.

Aortografia: Guiado por guia hidrofílica 0,035mm, um cateter de "pigtail" centimetrado é posicionado acima do colo proximal do aneurisma.

Prótese endovascular: Após o estudo da anatomia da aorta, ilíacas e do aneurisma do paciente a prótese endovascular deverá ser escolhida levando-se em conta as vantagens e desvantagens de cada uma como facilidade de introdução, mecanismo de fixação supra ou infra-renal, presença ou não de ganchos ou "barbs", etc. O cirurgião deverá ter a sua disposição vários números de próteses (próximos ao escolhido), várias extensões ilíacas, assim como "cuffs" ou extensões proximais.

Introdução da endoprótese: Por dentro do cateter "pigtail" centimetrado, introduzimos uma guia extra-rígida ( tipo Lunderquist-Cook) que conduzirá a endoprótese até o colo proximal do aneurisma. Em caso de prótese endovascular bifurcada, recomendamos o emprego de uma segunda guia Lunderquist na perna contra-lateral. O guia rígido no corpo principal ajuda a manter fixa a endoprótese bifurcada durante a manipulação para implante da perna contra-lateral. Em caso de não progressão da endoprótese na artéria ilíaca, dilatadores (18,20, 22 e 24 FF ) poderão ser usados de maneira cuidadosa e criteriosa.

Cateterismo da perna contra-lateral: após o implante da prótese endovascular bifurcada é necessário o cateterismo da perna contra-lateral da endoprótese. Devemos ter à mão cateteres com diversas curvas. Porém, com um cateter com curvatura de 120 graus (tipo kmp), um cateter Head Hunter , um Cateter Simons curva 1, podemos cateterizar o ramo contralateral em cerca de $95 \%$ dos casos. Em casos difíceis como posicionamento posterior da perna contra-lateral, grandes sacos aneurismáticos e outros, devemos lançar mão de outros recursos como o cateterismo anterógrado pela perna homo-lateral com cateter cobra ou Simons 1 empregando um laço para capturar o guia pela femural contra-lateral. Em alguns casos, devido a 
calcificações, dissecções ou tortuosidade das ilíacas, não conseguimos cateterizar a perna contra-lateral da prótese. Passamos então uma prótese monoilíaca ou endoprotese cônica na femural onde está implantada a prótese bifurcada, transformando assim em prótese monoilíaca. Neste caso, usaremos 1 oclusor para ocluir a ilíaca contra-lateral e uma prótese de Dacron reta para o "bypass" femoro-femoral refazendo o fluxo no membro contra-lateral.

Balão de Látex: Após o implante das endopróteses, principalmente as infra-reais, é aconselhável, na maioria dos casos, a expansão de um cateter balão oclusor de Látex (tipo CODA, RELIANT) para adaptar melhor a prótese endovascular ao colo aórtico e nos pontos de implante das extensões.

Avaliação final: Ao término do procedimento, devemos observar, com radioscopia simples, o posicionamento dos STENTS procurando dobras, mal posicionamentos ou rupturas. Em seguida, a aortografia final deverá ser bem examinada procurando vazamentos ("leaks"), estenoses nos ramos da endoprótese ou estenoses nas ilíacas devido ao traumatismo da parede vascular durante a passagem das endopróteses. Devemos ter sempre em mãos cateteres balão de angioplastia para expandir a ilíaca comum por dentro da extensão ilíaca , diâmetros de 10,12 e 14 mm e cateteres de diâmetro 7, 8 e 9 mm para a dilatação das ilíacas externas. Em caso de dobras das extensões ilíacas, devemos ter acesso a STENT balão expansível de 10 e $12 \mathrm{~mm}$ para manter a forma da extensão dentro da ilíaca comum.

Reconstrução da via de acesso: na maioria dos casos uma sutura contínua com fio de prolene é suficiente para reconstituir a artéria femoral. Porém, em casos de artérias finas, calcificadas, ou quando há utilização de endopróteses de grosso calibre pode haver laceração da artéria femoral, sendo necessárias endarterectomias com "patchs" ou mesmo interposição de prótese de Dacron no segmento lesado. 